\title{
NOTAS SOBRE EL CASO "SERNAC CON CENCOSUD": VALOR DEL SILENCIO Y PRESCRIPCIÓN DE ACCIÓN DE NULIDAD DE CLÁUSULAS ABUSIVAS*
}

Notes on the case "Sernac with Cencosud": Value of silence and

LIMITATION OF ACTION FOR ANNULMENT OF UNFAIR CLAUSES

Notes sur le cas “Serrnac avec Cencosud”: La valeur du silence

ET LA PRESCRIPTION DE L'ACTION D'ANNULATION DES

CLAUSES ABUSIVES

Hernán Corral TALCiAni ${ }^{* *}$

\section{UNA SÍNTESIS DEL CASO}

En diciembre de 2006, el Servicio Nacional del Consumidor interpuso demanda en juicio colectivo, de conformidad con los artículos 50 y siguientes de la Ley No 19.496, de Protección de los Derechos de los Consumidores, en contra de Cencosud Administradora de Tarjetas S.A. En ella pidió que se declaren nulas por abusivas dos cláusulas del contrato y del reglamento que rigen el uso de la tarjeta "Jumbo Más": una, la 16ª que permite a la empresa aumentar la comisión de administración con sólo informar a los usuarios, entendiéndose que éstos aceptaban si mantenían o usaban la tarjeta y no manifestaban voluntad de poner término al contrato en el plazo de 30 días; y otra, la 9a , por la que los usuarios otorgan mandato irrevocable a la empresa para constituir títulos ejecutivos que permitan a Cencosud cobrar el saldo que ésta fijara como adeudado. Se demandaron, además, los reembolsos e indemnizaciones por los cobros indebidos por el aumento de las comisiones que había sido informado en enero de 2006 (la comisión mensual fue aumentada de \$ 460 a \$990) y, por cierto, las multas correspondientes a las infracciones cometidas por la empresa por aplicación de las cláusulas impugnadas. La empresa demandada centró su defensa en negar que las cláusulas fueran abusivas, pero también interpuso la excepción de prescripción alegando que, al momento de notificarse la demanda (12 de enero de 2007), habían transcurrido los 6 meses de prescripción del artículo 26 de la Ley No 19.496.

\footnotetext{
*Este artículo fue aprobado para su publicación el 10 de junio de 2013.

** Abogado. Licenciado en Derecho de la Pontificia Universidad Católica de Chile. Doctor en Derecho por la Universidad de Navarra, España. Profesor Titular e investigador de jornada completa de la Universidad de los Andes. Correo electrónico hcorral@uandes.cl.
} 
El tribunal de primera instancia ${ }^{1}$ y la Corte de Apelaciones de Santiago ${ }^{2}$ juzgaron que no era abusiva la cláusula que otorgaba el mandato, pero que sí lo era aquella que permitía elevar las comisiones. El juzgado de letras, sin embargo, estimó que debía aplicarse parcialmente la prescripción de 6 meses, en cuanto cada pago mensual de la comisión aumentada en aplicación de la cláusula que se declaraba nula, era en sí misma una infracción con su propio plazo de 6 meses de prescripción. De este modo, dio lugar a la excepción de prescripción para todos los pagos percibidos por Cencosud hasta el 12 de julio de 2006. La Corte de Apelaciones no estuvo de acuerdo con la idea de que cada cuota mensual fuera una infracción, y consideró que se trataba de una sola contravención que se había consumado al informarse a los tarjetahabientes el alza de la comisión sin tomar en cuenta su consentimiento. Como desde ese hecho hasta la notificación de la demanda habían transcurrido en exceso los 6 meses previstos en el artículo 26 de la Ley No 19.496, declaró prescrita toda la responsabilidad de la empresa demandada.

La Corte Suprema casó el fallo ${ }^{3}$ al estimar que se había infringido la ley al aplicarse la prescripción de la responsabilidad infraccional a la acción de nulidad. En la sentencia de reemplazo declaró abusivas ambas cláusulas y desestimó la excepción de prescripción de la empresa, ya que juzgó que cada uno de los cobros realizados en ejecución de la modificación unilateral del contrato constituía por sí mismo una nueva infracción. Si bien mantuvo a firme la prescripción parcial acogida en primera instancia por no haber sido apelada por el demandante, la Corte ordenó indemnizar a los usuarios de tarjetas mediante la restitución de los dineros cobrados en exceso más reajustes e intereses y aplicó una multa de 50 Unidades de Fomento a la demandada.

Si bien son muchas las cuestiones jurídicas que pueden analizarse en este caso, en este breve comentario nos detendremos únicamente en dos de ellas: el alcance del silencio del consumidor y su configuración como aceptación tácita, y la prescripción de la acción para declarar la nulidad de las cláusulas que pueden calificarse de abusivas conforme al artículo 16 de la Ley No 19.496

\section{Sobre el alCANCE DEL Silencio y la aceptación tÁCita}

Dentro de las múltiples repercusiones que motivó el fallo de la Corte Suprema en la opinión pública llamaron nuestra atención las declaraciones de la Cámara de Comercio de Santiago. Su secretario general señaló que el fallo de la Corte Supre-

\footnotetext{
${ }^{1}$ Sentencia Décimo Juzgado Civil de Santiago, "Sernac con Cencosud", 30 de diciembre de 2010, Rol No 21910-2006.

${ }^{2}$ Sentencia Corte de Apelaciones de Santiago, "Sernac con Cencosud”, 3 de octubre de 2011, Rol No 9762011.

${ }^{3}$ Sentencia Corte Suprema "Sernac con Cencosud", 24 de abril de 2013, Rol No 12355-2011, LegalPublishing CL/JUR/880/2013.
} 
ma contenía novedades que obligan a revisar los contratos, y entre ellas mencionó "lo referente a la aceptación tácita reconocida en nuestro Código Civil, de que el silencio constituye derecho y las modalidades por deudor en las cobranzas son cambios importantes que deberán asumirse en los contratos" ${ }^{\prime 4}$.

La cuestión se refiere a la cláusula $16^{\circ}$ del contrato impugnado. Ésta decía textualmente: "Cualquier cambio de las condiciones de uso y privilegios de la tarjeta deberá ser informado por escrito al usuario, entendiéndose que éste acepta si mantiene o utiliza la tarjeta después de 30 días de expedida la comunicación respectiva. Si el usuario decidiere no aceptar las variaciones podrá poner término de inmediato al contrato mediante el aviso a la empresa y haciéndole entrega material de las tarjetas que hubiere recibido". De esta manera, cuando Cencosud quería alzar las comisiones de administración de la tarjeta, bastaba que lo decidiera unilateralmente y lo comunicara por escrito al usuario; si éste no decía nada y no ponía término al contrato en 30 días, se entendía que aceptaba la modificación y quedaba obligado a pagar la nueva tasa.

El caso más claro de consideración del silencio como manifestación de voluntad se daba cuando el usuario sólo mantenía la tarjeta, sin siquiera usarla. Más discutible podría ser el evento en que el usuario hacía uso de la tarjeta; la empresa demandada alegó que en tal caso había un supuesto, no de silencio, sino de aceptación tácita de voluntad, que tiene lugar, como sabemos, cuando no se manifiesta la voluntad por medio del lenguaje oral o escrito, sino por actuaciones o comportamientos que permiten deducir inequívocamente el asentimiento. Sin embargo, la Corte Suprema estimó que esto último no se daba tampoco porque la forma en que se comunicó al consumidor (incluir una nota en el costado derecho inferior en un estado de cuenta y en letra pequeña) no era un medio que permitiera razonablemente presumir que el usuario de la tarjeta haya procedido a sabiendas de que su actuación implicaba aceptar el alza de la comisión mensual.

Los dos casos, por tanto, son reconducidos a una forma de eficacia del silencio en el ámbito del consumo, lo que el fallo no puede aceptar: "Mientras no haya certeza de dicho conocimiento en cada tarjetahabiente, la circunstancia que hayan usado una tarjeta no es signo inequivoco o concluyente de aceptación a la modificación propuesta; por lo mismo, derivar de ello una aceptación, supone darle al silencio un sentido de manifestación de voluntad, que se encuentra expresamente prohibido por el artículo $3^{\circ}$ letra a) de la Ley $N^{\circ} 19.496^{\prime}$ " (considerando $6^{\circ}$ de la sentencia de reemplazo). En efecto, la norma citada dispone expresamente que "El silencio no constituye aceptación en los actos de consumo".

Pero ¿quiere decir esto, como parece sugerirlo el secretario general de la Cámara de Comercio, que en Derecho Civil general el silencio sí constituye aceptación o manifestación de voluntad de un acto jurídico o contrato? La respuesta es negativa.

${ }^{4}$ Diario El Mercurio, 26 de abril de 2013, cuerpo B, p. 2. 
Si bien el Código Civil se limita a señalar que para que una persona se obligue a otra por un acto o declaración de voluntad es necesario " $2^{\circ}$ que consienta en dicho acto o declaración...” (artículo 1445 del Código Civil), hay uniformidad en doctrina y jurisprudencia de que el mero silencio no constituye manifestación, ni siquiera tácita, de voluntad. No rige, en consecuencia, el refrán vulgar que reza "quien calla, otorga". Los profesores de Derecho Civil decimos que para efectos del consentimiento el adagio que rige es más bien "quien calla, no dice nada". Podría estimarse, en consecuencia, que la disposición de la Ley No 19.496, del Consumidor, no dispone nada distinto a lo que ya rige para el común de los negocios jurídicos; pero tampoco es tan así.

Veamos: en Derecho Civil la falta de significado jurídico del silencio es una regla general, pero no absoluta; se reconocen excepciones que se sistematizan en tres categorías: 1a) Cuando la misma ley le atribuye un significado al silencio;

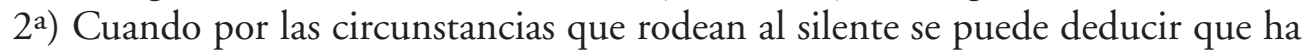
consentido ("silencio circunstanciado"), y 3o) Cuando las partes, haciendo uso de la autonomía privada, han previsto expresamente que el silencio de una de ellas deberá considerarse aceptación. Esta última facultad suele usarse con frecuencia en contratos de tracto sucesivo para disponer prórrogas automáticas; por ejemplo, es usual que en contratos de arrendamientos se disponga que el contrato durará un año, pero que si ninguna de las partes manifiesta voluntad contraria 30 días antes de que expire, se renovará automáticamente por otro año y así sucesivamente.

Es en este último caso donde se distancia el Derecho Civil común del Derecho del Consumo, y aquí adquiere importancia la disposición del artículo $3^{\circ}$ letra a) de la Ley No 19.496, sobre todo si se relaciona dicha norma con el artículo $4^{\circ}$ de la ley. Lo que sucede no es sólo que el silencio no constituya manifestación de voluntad, lo que también ocurre en el Derecho Civil, sino que esa regla no puede tener excepciones aunque así se haya estipulado en un contrato suscrito por el consumidor. Debe considerarse que la norma que niega eficacia de aceptación al silencio está en el artículo que declara cuáles son los derechos del consumidor (artículo 30), por lo que puede entenderse que la no consideración del silencio del consumidor como aceptación, es un derecho que la ley le concede. Si es un derecho, entonces, se aplica el artículo $4^{\circ}$ de la misma ley, según el cual "Los derechos establecidos por la presente ley son irrenunciables anticipadamente por los consumidores”. Luego, la cláusula del contrato impugnado, al prever que el silencio implicaba aceptación de las modificaciones introducidas en el contrato, constituía una renuncia anticipada al derecho señalado en el artículo $3^{\circ}$ letra a) de la Ley No 19.496 y, siendo una renuncia prohibida por el artículo $4^{\circ}$ de dicha ley, carece de efecto (no es nula, sino más bien inexistente o nula de pleno derecho).

Si la cláusula que da carácter de aceptación al silencio carece de eficacia, entonces, tiene razón la Corte Suprema al señalar que la cláusula 16 a del contrato puede ser calificada de abusiva en cuanto cae en el supuesto del artículo 16 letra a) de la Ley No 19.496, que señala que no producirán efecto en los contratos de 
adhesión aquellas cláusulas que "otorguen a una de las partes la facultad de dejar sin efecto o modificar a su solo arbitrio el contrato...”.

En suma, si bien en el Derecho Civil el silencio puede excepcionalmente tener valor de manifestación de voluntad si así lo estipulan las partes, en el Derecho del consumo ello no puede suceder y la máxima "quien calla no dice nada" adquiere un valor de norma de orden público indisponible.

\section{Sobre la PRESCRIPCIÓN DE LA ACCIÓN DE NULIDAD POR ABUSIVIDAD}

DE LAS CLÁUSULAS

La cuestión de la prescripción de la acción de nulidad estuvo presente durante todo el litigio pero no parece haber conseguido ser dilucidada, salvo en un punto que no deja de ser relevante: que a esta acción no es aplicable la prescripción prevista en el artículo 26 de la Ley No 19.496, esto es, la de 6 meses desde que se incurre en la infracción.

La Corte de Apelaciones, al revocar el fallo de primera instancia y absolver a la demandada en razón de haber transcurrido el referido plazo, vislumbró que se trataba de dos acciones distintas: una, era la dirigida a obtener la nulidad de las cláusulas abusivas y otra la destinada a hacer efectiva la culpa infraccional imponiendo la correspondiente multa a beneficio fiscal. Después de declarar prescrita la responsabilidad infraccional, intentó dejar cerrado el tema no dando lugar tampoco a la prescripción de la nulidad pero con un escueto fundamento: "Que, en lo que concierne a la acción destinada a declarar la nulidad de la cláusula novena del contrato, corresponde que sea rechazada la prescripción alegada, porque ni en el escrito respectivo ni en el que contiene el recurso de apelación se proporcionan los datos necesarios para concluir si se verificaron los supuestos necesarios que autorizan para asi declararlo, compartiendo esta Corte con [sic] lo concluido por el a quo en cuanto rechazó, en esa parte, la demanda..." (Considerando 13\%). La verdad es que la sentencia del tribunal a quo sólo hace referencia a la prescripción de la acción infraccional y no a la de nulidad.

Deducidos recursos de casación en la forma y fondo en contra de la sentencia de segunda instancia, será este punto el que servirá a la Corte Suprema para casar el fallo. En efecto, considerará que al haberse pronunciado sobre una excepción de prescripción que no había sido interpuesta ni en primera ni en segunda instancia la Corte de Apelaciones había fallado ultra petita. Desestimó, en consecuencia, que el plazo de 6 meses fuera una prescripción general aplicable a todas las acciones que surjan a favor del consumidor en virtud de los incumplimientos a la Ley No 19.496, y acotó su alcance a la acción para hacer efectiva la responsabilidad infraccional: "Que la excepción de prescripción opuesta por la demandada está basada en el artículo 26 de la Ley $N^{\circ}$ 19.496, norma que únicamente se refiere a la responsabilidad contravencional [....] No puede entenderse, entonces, aplicable el articulo 26 en análisis para estimar prescrita la acción por la cual se pretende se declare abusiva una 
determinada cláusula, pues, esta sanción la estatuye directamente la ley en su artículo 16, y la acción correspondiente se regula en lo dispuesto en los articulos $16 \mathrm{~B}$ y $50 \mathrm{~A}$, inciso segundo. Por lo mismo, aunque se pudiera entender prescrita la responsabilidad contravencional que corresponda, para los efectos de condenar a la infractora al pago de una multa, conforme la ley lo establece, de ninguna manera este hecho obligaria a estimar prescrita la acción destinada a que se declare nula la respectiva cláusula, pues se trata de acciones distintas" (considerando $10^{\circ}$ de la sentencia de casación).

No obstante, la sentencia de reemplazo sólo se pronuncia sobre la prescripción de la responsabilidad infraccional (rechazándola salvo en la parte en la que la había aceptado el juez de primera instancia), y nada dice sobre el régimen de prescripción de la acción de nulidad por abusividad de las cláusulas de un contrato de adhesión, como no sea que ella no se rige por el artículo 26 de la Ley No 19.496 (considerando 13\%).

A nuestro juicio, al no disponer nada la Ley No 19.496 sobre este tema deberá recurrirse al régimen común de la nulidad contemplado en el título XX del libro IV del Código Civil y aplicarse la prescripción de la acción de nulidad absoluta -sería un caso de nulidad parcial por objeto ilícito por estar la cláusula prohibida por las leyes: cfr. artículo 1466 del Código Civil-, que exige un lapso de diez años desde la fecha del acto o contrato (artículo 1683 del Código Civil).

El término es suficientemente extenso para proteger a los consumidores afectados, pero además bien podría pensarse que tratándose de un contrato de tracto sucesivo la acción de nulidad se mantiene, al menos para evitar la aplicación de las cláusulas abusivas hacia el futuro. Sería poco sensato admitir que una cláusula que es considerada injusta y contraria a la buena fe contractual se saneara después de un cierto lapso de tiempo (por largo que éste fuese) y se legitimara así que una de las partes pudiera seguir desarrollando conductas abusivas en perjuicio de la otra. Pero esta idea merecería un desarrollo más extenso y profundo que el que permite un comentario como el que hemos intentado realizar en estas líneas. 